\title{
Association between a history of depression and anti-müllerian hormone among late-reproductive aged women: the Harvard study of moods and cycles
}

Samuel W. Golenbock1, Lauren A. Wise1, Geralyn M. Lambert-Messerlian²,3, Elizabeth E. Eklund ${ }^{2,3}$ and Bernard L. Harlow ${ }^{1 *}$ (D)

\begin{abstract}
Background: There is conflicting evidence regarding the association between a history of depression and risk of early menopause. In a cohort of premenopausal women, we investigated the association between depression history and ovarian reserve, as measured by anti-müllerian hormone (AMH).

Methods: The Harvard Study of Moods and Cycles (HSMC) was a prospective cohort study of women living in the Boston, MA metropolitan-area (1995-1999). Women aged 36-45 years at cohort entry (1995) were sampled from seven Boston metropolitan-area communities using census directories. We measured serum AMH in early-follicular phase venous blood specimens from 141 women with a Structured Clinical Interview for DSM-IV (SCID)-confirmed history of depression and 228 without such a history. We calculated prevalence ratios (PR) for the association between characteristics of depression history and low AMH ( $\leq 1.4 \mathrm{ng} / \mathrm{mL})$, adjusting for several potential confounders.

Results: The prevalence of low AMH was similar among depressed (57.5\%) and non-depressed (57.9\%) women (Adjusted [Adj] PR $=0.90,95 \% \mathrm{Cl}: 0.75,1.08$ ). Among depressed women, results were not appreciably different among those who had ever used antidepressants and those with comorbid anxiety. Modest inverse associations between depression and low AMH were seen among women aged 36-40 years (Adj PR $=0.75,95 \%$ Cl: 0.52, 1.09) and nulliparous women (Adj PR $=0.77,95 \% \mathrm{Cl}: 0.59,1.00$ ). No dose-response association with greater duration or length of depressive symptoms was observed.

Conclusions: Overall, the prevalence of low AMH was similar for depressed and non-depressed women 36-45 years of age. Surprisingly, among younger and nulliparous women, those with a history of depression had a slightly reduced prevalence of low $\mathrm{AMH}$ relative to those without such a history. These results do not indicate reduced ovarian reserve among women with a history of depression.
\end{abstract}

Keywords: Anti-müllerian hormone, Depression, premenopausal women, Ovarian reserve

* Correspondence: harlow@bu.edu

'Department of Epidemiology, Boston University School of Public Health, 715 Albany St, Boston, MA 02118, USA

Full list of author information is available at the end of the article

(c) The Author(s). 2020 Open Access This article is licensed under a Creative Commons Attribution 4.0 International License, which permits use, sharing, adaptation, distribution and reproduction in any medium or format, as long as you give appropriate credit to the original author(s) and the source, provide a link to the Creative Commons licence, and indicate if changes were made. The images or other third party material in this article are included in the article's Creative Commons licence, unless indicated otherwise in a credit line to the material. If material is not included in the article's Creative Commons licence and your intended use is not permitted by statutory regulation or exceeds the permitted use, you will need to obtain permission directly from the copyright holder. To view a copy of this licence, visit http://creativecommons.org/licenses/by/4.0/ The Creative Commons Public Domain Dedication waiver (http://creativecommons.org/publicdomain/zero/1.0/) applies to the data made available in this article, unless otherwise stated in a credit line to the data. 


\section{Introduction}

As women age, they encounter profound changes in reproductive function and associated health. Ovarian reserve is established at birth and declines with age, such that women in menopause have essentially lost their store of ovarian follicles and no longer experience menstrual cycles. The transition to menopause is a complex process involving multiple stages characterized by endocrine changes, dysregulated folliculogenesis, and physiologic and psycho-social symptoms. The menopausal transition has been studied in detail and characterized according to stages in a prospective, longitudinal, multicenter Study of Women's Health Across the Nation [1]. Changes in mood, sleep, and headache commonly occur as women transition to menopause [2]. In particular, there is evidence that symptoms of depression increase over the course of the menopausal transition [3]. The biological basis for increased risk of depression with aging among women has not been determined with certainty.

Declining endogenous estradiol concentrations are a hallmark of the menopausal transition and may be associated with susceptibility to depression [4]. For example, depressive episodes during the menopausal transition cluster in the late stages coincident with significant loss of estradiol, and other studies reported that depressive symptoms declined with exogenous estradiol treatment [5].

Age-related depression in women and various reproductive hormones have been studied extensively in the past, with the exception of anti-müllerian hormone. Antimüllerian hormone (AMH) is a glycoprotein hormone produced by the granulosa cells of pre-antral ovarian follicles that acts as a local modulator of folliculogenesis. As women age and the pool of growing ovarian follicles declines, there is a corresponding decrease in serum AMH levels. The decline in circulating AMH occurs throughout the reproductive lifespan until about one year before menopause, when levels become undetectable by current assay methods [6-8]. Prospective studies have found that serum levels of AMH are highly predictive of age at natural menopause [8-11], including those with early onset [10]. Furthermore, because $\mathrm{AMH}$ is an intra-ovarian factor produced in the small pre-antral follicles, there is relatively little variation in serum levels across the normal menstrual cycle [12, 13]. It is therefore considered a convenient biomarker as blood specimens can be drawn on any day of the cycle.

The age at which natural menopause occurs varies considerably among women, between 44 and 54 years, with an average age of 51 years $[14,15]$. In addition to chronological age, the rate of decline in ovarian reserve is influenced by genetics [16], smoking [6], and perhaps ethnicity [17] among other variables. Smoking, poor selfrelated health, and high physical activity have been associated with an earlier age at final menstrual period [18].
Some studies suggest that a history of major depression may also be associated with an earlier decline in ovarian function. In one case-control study, Harlow et al. [19] observed an association between a self-reported history of medically-treated depression and early natural menopause. In a later study by the same investigators, women with a history of depression who reported antidepressant use were found to have nearly three times the rate of onset of perimenopause relative to those without a history of depression [20].

The association between depression and AMH concentrations is unexplored to our knowledge. We performed a cross-sectional analysis to test the hypothesis of an association between a history of major depression and ovarian reserve, as measured by $\mathrm{AMH}$, in a cohort of premenopausal women.

We hypothesize that women with a history of depression may show an earlier or more pronounced age-related decrease in serum AMH levels compared to women with no history of major depression.

\section{Materials and methods Study population}

Data for the current study were derived from the Harvard Study of Moods and Cycles (HSMC). The HSMC (1995-1999) was a prospective cohort study of late reproductive-aged women with and without a history of major depressive disorder (MDD). The study cohort was recruited from a population-based sample of approximately 6000 women between 36 and 45 years of age residing in seven Boston metropolitan area communities, identified using census directories.

Eligible women were mailed an initial two-page screening questionnaire to assess current menopausal status and depression history. Women completed the 20-item Center for Epidemiologic Studies (CES-D) depression symptoms inventory. CES-D scores of 24 or greater are highly suggestive of major depression, while scores below 16 indicate mild to no depressive symptoms [21]. After receiving a $74 \%$ response rate $(N=$ 4572), and excluding an additional 408 individuals who did not meet pre-specified inclusion criteria (e.g. outside specified age range, postmenopausal), the target population consisted of 4161 women from which a sample of those with and without a history of MDD could be drawn.

As part of the initial screening, participants with CES-D scores $>24$ or a self-reported history of depression that required pharmacological or psychiatric therapy were invited to be enrolled as the cohort with a depression history. Those with CES-D scores $<16$ and no self-reported history of depression history or treatment were invited to be enrolled as the cohort without a depression history. Eligible women further participated in structured clinical interviews 
for depression (SCID) based on the Diagnostic and Statistical Manual of Mental Disorders, fourth edition (DSM-IV) [22]. Thus, 332 women who met DSM-IV criteria for past or current MDD and 644 women with no history of MDD were enrolled in the HSMC. The remaining 3185 women from the target population were not enrolled in the study. For the purposes of the current study, women with any history of depression are referred to as "depressed" while those with no history of MDD are referred to as "non-depressed." The Hamilton Rating Scale for Depression (HAM-D) [23] was also administered at baseline to measure depression symptom severity. Additional questionnaire items asked whether participants had ever used prescription antidepressants for a period of six months or more, how many depressive episodes they had experienced, age at the first depressive episode, and the total duration of all depressive episodes combined.

Details on sampling procedures and demographic comparisons of enrolled and non-enrolled women have been described previously [24, 25]. The HSMC was approved by the Institutional Review Board at Brigham and Women's Hospital and all participants provided written informed consent.

Participants provided early follicular phase (day $2-4$ of the menstrual cycle) blood specimens at study enrollment to measure reproductive hormones. For this analysis, we used baseline samples from a subset of women with and without a history of depression who were able to provide menstrually-timed blood specimens that were also used in a previous analysis of inhibin B [26].

\section{Anti-müllerian hormone (AMH) immunoassay}

Serum samples were tested using the picoAMH kit (Ansh Labs, Webster, TX), with an assay sensitivity of $6 \mathrm{pg} / \mathrm{ml}$, intra-assay $\mathrm{CV}<6.5 \%$ and inter-assay $\mathrm{CV}<11 \%$. This assay is FDA approved and a clinically acceptable method of AMH measurement [27, 28]. Samples were analyzed for $\mathrm{AMH}$ in 401 women who provided menstrual-timed blood specimens at study enrollment and who were assessed in an earlier study of Inhibin-B that required multiple specimens [26]. The current analysis omitted participants who reported physician-diagnosed polycystic ovarian syndrome (PCOS) $(n=3)$, as this has been associated with increased AMH levels [29]. Participants with AMH levels $\geq 5.0 \mathrm{ng} / \mathrm{mL}(n=29)$ were also omitted as this may be an indication of undiagnosed PCOS [30]. After these exclusions, 141 depressed women and 228 nondepressed women were available for analysis of baseline AMH levels. We assessed demographic and reproductive differences between women in whom we did and did not assess AMH levels. We found that women with and without AMH analyses were similar for most demographic and reproductive variables available. The exception was that a greater proportion of those with $\mathrm{AMH}$ analyzed were: a) depressed (43.7\% vs $36.1 \%)$ and b) nulligravid (33.6\% vs $16.2 \%)$. We address the impact of this limitation in the Discussion below.

\section{Demographic and reproductive characteristics}

Self-reported data on demographics, reproductive health, medical history, and other lifestyle factors were collected during in-person interviews at baseline. Sociodemographic characteristics included age, race, education level and marital status. Body weight and height were used to calculate baseline body mass index $\left(\mathrm{BMI}, \mathrm{kg} / \mathrm{m}^{2}\right)$, and participants were categorized into four BMI groups (underweight $<20$, normal 20-24.9, overweight 25-29.9 and obese $\geq 30$ ). Medical questionnaires elicited data on menstrual history, such as oral contraceptive use, prior pregnancies, number of livebirths, age at menarche, and average cycle length. Smoking status was assessed and categorized into groups (current/former and neversmoker) and pack-years (the number of packs of cigarettes smoked per day multiplied by the number of active smoking years) were calculated as a measure of smoking intensity. Select covariates were examined as potential effect measure modifiers, including age, parity, infertility history, current cycle regularity, smoking status, and BMI. Infertility history was defined as responding yes to the question "Did you ever try for more than 2 years to get pregnant or have problems carrying a pregnancy?" Current cycle regularity was defined as responding yes to the question "Are your cycles now generally regular, that is, usually predictable within 10 days?"

\section{Statistical analysis}

Baseline AMH levels were dichotomized based on a clinically relevant threshold of $1.4 \mathrm{ng} / \mathrm{mL}$. Diminished ovarian reserve is consistent with low AMH levels [31] defined as less than or equal to $1.4 \mathrm{ng} / \mathrm{mL}$ after accounting for use of the Ansh AMH assay method [27].

We used a modified Poisson regression model with a robust error variance [32] to estimate prevalence ratios (PR) and 95\% confidence intervals (CI) for the association between depression history and AMH levels $\leq 1.4$ $\mathrm{ng} / \mathrm{mL}$ (i.e., diminished ovarian reserve). Age- and covariate-adjusted models were presented for depression and its characteristics. Potential confounders were identified from a review of the literature and the drawing of a directed acyclic graph. Covariates included in final multivariable models were age, BMI, smoking status, pack-years of smoking, parity, current menstrual cycle irregularity, age at menarche, and lifetime duration of oral contraceptive use. These variables were included in our adjusted models based on meeting criteria for confounding ( $>10 \%$ difference in crude versus adjusted risk estimates) or because previous literature indicated their importance as confounders. In addition to categorical 
Table 1 Baseline health and sociodemographic characteristics of women with and without a history of depression, Harvard Study of Moods and Cycles, 1995-1998

\begin{tabular}{|c|c|c|c|c|}
\hline & \multicolumn{2}{|c|}{$\begin{array}{l}\text { History of Depression } \\
(\boldsymbol{n}=141)\end{array}$} & \multicolumn{2}{|c|}{$\begin{array}{l}\text { No History of Depression } \\
(\boldsymbol{n}=228)\end{array}$} \\
\hline & $\mathrm{n}$ & $\%$ & $\mathrm{n}$ & $\%$ \\
\hline \multicolumn{5}{|l|}{ Age, years } \\
\hline $36-37$ & 17 & 12.1 & 36 & 15.8 \\
\hline $38-39$ & 28 & 19.9 & 48 & 21.1 \\
\hline $40-41$ & 38 & 27.0 & 65 & 28.5 \\
\hline $42-43$ & 26 & 18.4 & 50 & 21.9 \\
\hline $44-45$ & 32 & 22.7 & 29 & 12.7 \\
\hline \multicolumn{5}{|l|}{ Race/Ethnicity } \\
\hline Non-Hispanic White & 136 & 96.4 & 216 & 94.7 \\
\hline Black, Hispanic/Latina, Asian, Other & 5 & 3.6 & 12 & 5.3 \\
\hline \multicolumn{5}{|l|}{ Education } \\
\hline Less than college & 32 & 22.7 & 71 & 31.1 \\
\hline College & 41 & 29.1 & 77 & 33.8 \\
\hline Graduate School & 68 & 48.2 & 80 & 35.1 \\
\hline \multicolumn{5}{|l|}{ Marital status } \\
\hline Married & 89 & 63.1 & 162 & 71.0 \\
\hline Single/Never married & 27 & 19.2 & 48 & 21.1 \\
\hline Divorced/separated & 25 & 17.7 & 18 & 7.9 \\
\hline \multicolumn{5}{|l|}{ Body mass index (BMI), $\mathrm{kg} / \mathrm{m}^{2}$} \\
\hline Underweight $(<20)$ & 26 & 18.4 & 41 & 18.0 \\
\hline Normal weight (20-24.9) & 61 & 43.3 & 97 & 42.5 \\
\hline Overweight (25-29.9) & 35 & 24.8 & 57 & 25.0 \\
\hline Obese $(\geq 30)$ & 19 & 13.5 & 33 & 14.5 \\
\hline \multicolumn{5}{|l|}{ Smoking history } \\
\hline Never smoker & 64 & 45.4 & 121 & 53.1 \\
\hline Former smoker & 54 & 38.3 & 78 & 34.2 \\
\hline Current smoker & 23 & 16.3 & 29 & 12.7 \\
\hline \multicolumn{5}{|l|}{ Age at menarche, years } \\
\hline$\leq 11$ & 27 & 19.2 & 36 & 15.8 \\
\hline $12-14$ & 85 & 60.3 & 141 & 61.8 \\
\hline$\geq 15$ & 29 & 20.6 & 51 & 22.4 \\
\hline \multicolumn{5}{|l|}{ Parity (livebirths) } \\
\hline Nulliparous & 84 & 59.6 & 85 & 37.3 \\
\hline 1 & 23 & 16.3 & 33 & 14.5 \\
\hline$\geq 2$ & 34 & 24.1 & 110 & 48.3 \\
\hline \multicolumn{5}{|l|}{ Gravidity (pregnancies) } \\
\hline Nulligravid & 60 & 42.6 & 64 & 28.1 \\
\hline $1-2$ & 49 & 34.8 & 74 & 32.5 \\
\hline$\geq 3$ & 32 & 22.7 & 90 & 39.5 \\
\hline \multicolumn{5}{|l|}{ Oral contraceptive use, years } \\
\hline Never & 38 & 27.0 & 75 & 32.9 \\
\hline 1 & 36 & 25.5 & 51 & 22.4 \\
\hline $2-5$ & 34 & 24.1 & 51 & 22.4 \\
\hline
\end{tabular}


Table 1 Baseline health and sociodemographic characteristics of women with and without a history of depression, Harvard Study of Moods and Cycles, 1995-1998 (Continued)

\begin{tabular}{|c|c|c|c|c|}
\hline & \multicolumn{2}{|c|}{$\begin{array}{l}\text { History of Depression } \\
(\boldsymbol{n}=141)\end{array}$} & \multicolumn{2}{|c|}{$\begin{array}{l}\text { No History of Depression } \\
(\boldsymbol{n}=228)\end{array}$} \\
\hline & $n$ & $\%$ & $n$ & $\%$ \\
\hline$>5$ & 33 & 23.4 & 51 & 22.4 \\
\hline \multicolumn{5}{|l|}{ Menstrual cycle regularity ${ }^{a}$} \\
\hline Irregular & 8 & 5.7 & 21 & 9.2 \\
\hline Regular & 133 & 94.3 & 207 & 90.8 \\
\hline \multicolumn{5}{|l|}{ Menstrual cycle length, days } \\
\hline$<26$ & 24 & 17.0 & 36 & 15.8 \\
\hline $26-29$ & 85 & 60.3 & 142 & 62.3 \\
\hline$\geq 30$ & 32 & 22.7 & 50 & 21.9 \\
\hline History of infertility ${ }^{b}$ & 16 & 11.4 & 50 & 21.9 \\
\hline Ever used antidepressants $^{c}$ & 88 & 62.4 & 3 & 1.3 \\
\hline
\end{tabular}

a. Question asked "Are your cycles now generally regular, that is, usually predictable within 10 days?

b. Question asked "Did you ever try for more than 2 years to get pregnant or have problems carrying a pregnancy?"

c. Participants were asked if they had ever taken antidepressant medications for a period of 6 months of more

analyses, we used restricted cubic splines to model the association between selected variables (depression history, age, BMI, smoking) and AMH as a continuous outcome variable, without imposing linearity on the associations [33]. Each spline curve was fit with four knot points for AMH concentrations at the 20th, 40th, 60th, and 80th percentiles (0.100, 0.750, 1.750, $3.250 \mathrm{ng} / \mathrm{nl})$.

Effect measure modification was assessed by stratifying on selected covariates that we hypothesized a priori might modify the association between depression and $\mathrm{AMH}$. These variables included age, parity, smoking history, infertility history, and history of OC use. Associations between covariates and low AMH were also examined within each of the depressed and non-depressed cohorts. In secondary analyses, AMH levels were examined as a continuous outcome measure using restricted cubic splines to confirm model results. All analyses were performed in SAS v9.4 (SAS Institute, Cary, NC).

\section{Results}

Although all women were between 36 and 45 years of age (Table 1), depressed women were slightly older than non-depressed women (23\% vs. $13 \%$ were $44-45$ years old, respectively). In addition, depressed women were more likely to have ever smoked cigarettes (55\% depressed vs. $47 \%$ non-depressed) or to have used oral contraceptives (73\% depressed vs. 67\% non-depressed) in their lifetime. Depressed women were considerably more likely to be nulliparous (60\% depressed vs. $37 \%$ non-depressed), but reported lower two-year infertility rates (11\% depressed vs. $22 \%$ non-depressed). Body mass index (BMI), race, age at menarche, and average menstrual cycle lengths were similar between depressed and non-depressed women.

Overall, there was little association between depression history and baseline serum AMH levels (Table 2). The unadjusted prevalence of low AMH $(\leq 1.4 \mathrm{ng} / \mathrm{mL})$ was similar for depressed (57.5\%) and non-depressed (57.9\%) women, while depressed women had marginally higher serum levels of AMH $(\mu=1.60 \mathrm{ng} / \mathrm{mL}, \mathrm{sd}=1.3)$ compared with non-depressed women $(\mu=1.44 \mathrm{ng} / \mathrm{mL}$, $\mathrm{sd}=$ 1.3). However, after adjusting for covariates, depression history showed a modest inverse association with low AMH (PR $=0.90,95 \%$ CI: 0.75, 1.08), indicating a slightly lower likelihood of low ovarian reserve among depressed women.

Results did not reveal a monotonic inverse association between greater depression severity and AMH levels. Associations for depressed women who had taken antidepressants $(\mathrm{PR}=0.89,95 \% \mathrm{CI}: 0.72,1.11)$ and those with comorbid anxiety at baseline (PR $=0.91,95 \% \mathrm{CI}$ : 0.73, 1.13) were similar to that of non-depressed women (Table 2). The association with low AMH was somewhat more pronounced for depressed than non-depressed women with lower symptom severity scores (HAM-D < 8) $(\mathrm{PR}=0.81$, 95\% CI: 0.59, 1.11). Depressed women with later ages at first onset of depression (age $\geq 30)(P R=0.81$, 95\% CI: $0.61,1.09)$ and shorter total duration of depressive episodes (<12 months) ( $\mathrm{PR}=0.85,95 \% \mathrm{CI}: 0.68,1.07)$ were slightly more likely to show diminished ovarian reserve compared with non-depressed women, but the latter did not show evidence of a dose-response association.

After stratifying by age (Table 3), PRs for the association between depression and low $\mathrm{AMH}$ were 0.75 among women aged 36-40 years (95\% CI: 0.52, 1.09) 
Table 2 Association of depression history and severity characteristics with low levels of anti-müllerian hormone $(\leq 1.4 \mathrm{ng} / \mathrm{mL})$, Harvard Study of Moods and Cycles, 1995-1998

\begin{tabular}{|c|c|c|c|c|}
\hline \multirow{2}{*}{\multicolumn{2}{|c|}{$\frac{\text { AMH Level }}{\leq 1.4 \mathrm{ng} / \mathrm{mL}}$}} & \multirow{3}{*}{$\begin{array}{l}\text { Age-adjusted } \\
\text { PR }\end{array}$} & \multicolumn{2}{|c|}{ Multivariable $†$} \\
\hline & & & & \\
\hline $\mathrm{n}$ & $\%$ & & \multicolumn{2}{|c|}{ Adjusted PR (95\% Cl) } \\
\hline 132 & 57.9 & 1.00 & 1.00 & Reference \\
\hline 81 & 57.5 & 0.92 & 0.90 & $(0.75,1.08)$ \\
\hline
\end{tabular}

Model 2

Antidepressant use

Depressed, never used antidepressants

Depressed, ever used antidepressants

Model 3

Depression \& anxiety

Depression only

Depression and anxiety

Model 4

Hamilton Depression Rating Scale (HAM-D) $)^{b}$

History of depression, HAM-D $<8$

History of depression, HAM-D $\geq 8$

Model 5

Age of depression onset, years ${ }^{c}$

$<25$
$25-29$
$\geq 30$

Model 6

Number of depressive episodes ${ }^{c}$

$$
1-2
$$

$\geq 3$

Model 7

Total duration of depressive episodes, months ${ }^{c}$

$$
\begin{aligned}
& <12 \\
& 12-35 \\
& \geq 36
\end{aligned}
$$

Models adjusted for age, age at menarche, cycle irregularity, parity, oral contraceptive use, smoking status at baseline, smoking pack-years, and body mass index (BMI). Analyses were restricted to those with $\mathrm{AMH}<5.0 \mathrm{ng} / \mathrm{mL}$, a potential indicator of elevated AMH due to polycystic ovary syndrome (PCOS)

a. Non-depressed serve as reference group for all exposure variables (displayed in first row only)

b. Hamilton Depression scores were missing for $n=27$ (apx. 7\% from both depressed and non-depressed cohort)

c. 'Age of onset' variable missing 5 responses; 'number of episodes' and 'duration' variables missing 6 responses

and 1.16 among women aged $41-45$ years (95\% CI: 0.95 , 1.40). Similarly, PRs for the association between depression and low AMH were 0.77 among nulliparous women (95\% CI: $0.59,1.00)$ and 1.08 among parous women (95\% CI: $0.85,1.38)$. Results did not vary appreciably by menstrual cycle regularity (regular/irregular), smoking status (never/ever), or BMI (normal/overweight/obese).

Restricted cubic spline curves, in which AMH was modeled as a continuous variable, were generally consistent with the categorical analyses (Figs. 1, 2 and 3). Specifically, we observed a modest positive association between serum AMH levels and depression prevalence (Fig. 1), as well as the age-specific associations observed in previouslydescribed stratified analyses (Figs. 2 and 3). Participant age was associated with lower AMH (Supplemental Fig. 1), as were pack-years of smoking (Supplemental Fig. 2). There was little association between BMI and AMH (Supplemental Fig. 3). 
Table 3 Association of depression history with low levels of anti-müllerian hormone $(\leq 1.4 \mathrm{ng} / \mathrm{mL})$, stratified by oral contraceptive use, parity, cycle regularity, smoking and body mass index (BMI), Harvard Study of Moods and Cycles, 1995-1998

\begin{tabular}{|c|c|c|c|c|c|}
\hline \multirow{3}{*}{ Age, years } & \multicolumn{2}{|c|}{ AMH Level $(\leq 1.4 \mathrm{ng} / \mathrm{mL})$} & \multirow{2}{*}{$\begin{array}{l}\text { Age-Adjusted } \\
\text { PR }^{\mathrm{a}}\end{array}$} & \multirow{2}{*}{\multicolumn{2}{|c|}{$\frac{\text { Multivariable }+}{\text { Adjusted PR }(95 \% \mathrm{Cl})}$}} \\
\hline & \multirow[t]{2}{*}{$\mathrm{n}$} & \multirow[t]{2}{*}{$\%$} & & & \\
\hline & & & & & \\
\hline $36-40$ & 85 & 45.2 & 0.74 & 0.75 & $(0.52,1.09)$ \\
\hline $41-45$ & 128 & 70.7 & 1.11 & 1.16 & $(0.95,1.40)$ \\
\hline Parity (livebirths) ${ }^{c}$ & & & & & \\
\hline Parous & 117 & 58.5 & 1.07 & 1.08 & $(0.85,1.38)$ \\
\hline Nulliparous & 96 & 56.8 & 0.78 & 0.77 & $(0.59,1.00)$ \\
\hline Infertility & & & & & \\
\hline Fertile & 178 & 58.8 & 0.96 & 0.98 & $(0.81,1.18)$ \\
\hline Infertile & 35 & 53.0 & 0.58 & 0.65 & $(0.32,1.33)$ \\
\hline Cycle regularity $b, c$ & & & & & \\
\hline Regular Cycle & 191 & 56.2 & 0.97 & 0.96 & $(0.80,1.16)$ \\
\hline Irregular Cycle & 22 & 75.9 & 0.75 & 0.70 & $(0.38,1.29)$ \\
\hline Baseline smoking status & & & & & \\
\hline Ever-smokers & 29 & 55.8 & 0.68 & 0.79 & $(0.50,1.26)$ \\
\hline Never-smokers & 184 & 58.0 & 0.97 & 0.96 & $(0.80,1.16)$ \\
\hline Body mass index (BMI), kc & & & & & \\
\hline Normal weight $(<25)$ & 128 & 56.9 & 0.87 & 0.85 & $(0.68,1.08)$ \\
\hline Overweight (25-29.9) & 55 & 59.8 & 1.19 & 1.22 & $(0.85,1.73)$ \\
\hline Obese $(\geq 30)$ & 30 & 57.7 & 0.75 & 0.80 & $(0.48,1.35)$ \\
\hline
\end{tabular}

† Covariates included age, age at menarche, irregular cycle, pack years smoking, and body mass index (BMI)

a. 'Age-adjusted' model reports crude prevalence ratios for stratified age-groups

b. Did not adjust for parity

c. Did not adjust for oral contraceptive use

\section{Discussion}

We hypothesized that women with a history of depression would show an earlier decrease in serum AMH levels, after controlling for age, based on prior studies suggesting that early perimenopause occurs to a greater extent among depressed women. However, our results do not support this hypothesis. Our data also showed no appreciable association between depression severity and serum AMH levels. Results for various depression characteristics (e.g., age at onset, duration of illness, number of episodes) also showed inconsistent associations with $\mathrm{AMH}$ concentrations. Finally, results based on a categorical cut point for "low" AMH concentrations $(\leq 1.4 \mathrm{ng} / \mathrm{ml})$ were similar to those based on $\mathrm{AMH}$ concentrations as a continuous variable.

Prior studies consistently describe an age-related decline in serum AMH concentrations [34-37], as well as modest reductions in serum $\mathrm{AMH}$ concentrations related to cigarette smoking $[6,38]$. BMI has been reported to have an inverse relationship with serum $\mathrm{AMH}$ in some [39-42], but not all $[6,43,44]$, studies. In the present study, AMH concentrations tended to decrease with advancing age and greater intensity of cigarette smoking, but little association was observed for BMI. Women with a history of depression were slightly older and were more frequently smokers, yet, analysis of AMH concentrations with adjustment for covariates did not appreciably alter results.

A prior study of the relationship between depressive symptoms (as measured by the Beck Depression Inventory) and $\mathrm{AMH}$ concentrations [45] in late-reproductive aged women corroborates our findings. The authors reported similar AMH levels regardless of depression. However, their conclusion was based on results from a bivariate analysis that did not adjust for age and other covariates. It is noteworthy that psychological stress, a different but related neuropsychological phenomenon, was associated with lower AMH concentrations among a large group of infertile women [46].

We previously examined the association between depression and inhibin B in the present subcohort [26]. In that analysis, inhibin B was not markedly different between the depressed and non-depressed women at baseline or during 18 months of follow-up, and showed a slight inverse association. Inhibin B increases during the follicular phase of the menstrual cycle and peaks with the formation of the dominant follicle mid-cycle. This follicle growth reflects a gonadotropin-dependent process. Although ovarian granulosa cells are the source of both inhibin B and $A M H$, the roles and secretion of these hormones are quite different. 


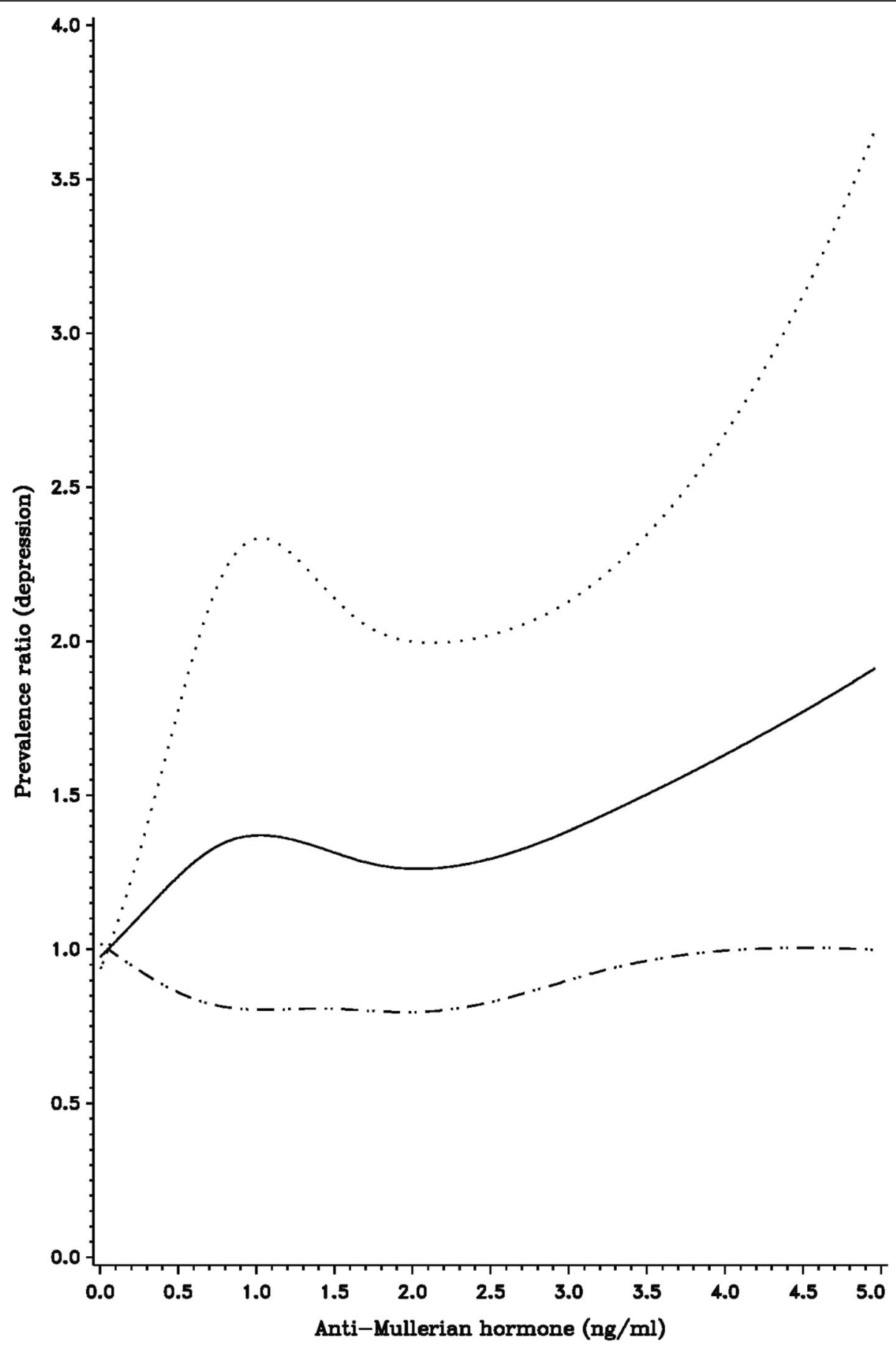

Fig. 1 Restricted cubic spline displaying the association between depression history and AMH levels, with knot points at AMH levels of 0.100, $0.750,1.750,3.250$. Adjusted for age, cycle irregularity, BMl, pack-years of smoking, age at menarche, and history of OC use

Unlike inhibin B, AMH is a product of the small pre-antral follicles and is independent of FSH secretion. AMH is a direct measure of the follicles in reserve in the ovary, with concentrations highly correlated with chronological age and ultrasound-determined antral follicle counts. AMH is superior to inhibin $\mathrm{B}$ in predicting ovarian aging and menopause [47]. One might speculate that either ovarian reserve or ovarian development is altered by depression, but collectively these data suggest neither is true. Although, in this same dataset, we previously showed an association between depression and earlier onset of perimenopause based on menstrual cycle changes [20]. 


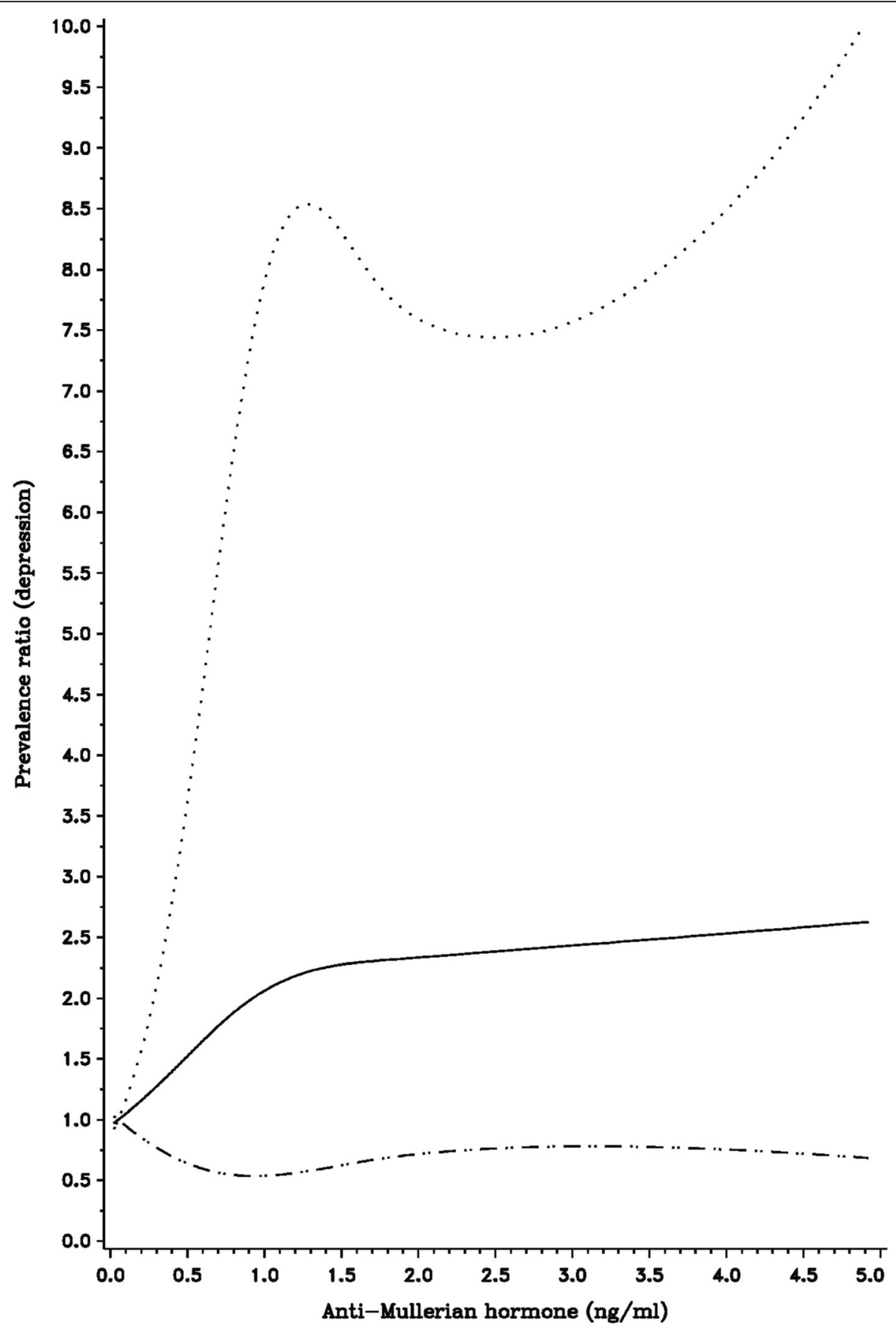

Fig. 2 Restricted cubic spline displaying the association between depression history and AMH levels among women aged 35-39years at enrollment, with knot points at AMH levels of 0.100, 0.750, 1.750, 3.250. Adjusted for cycle irregularity, BMl, pack-years of smoking, age at menarche, and history of $O C$ use

Depression may, on the other hand, influence the reproductive axis, perhaps primarily at the level of the pituitary gland and/or hypothalamus. In the original HSMC study of 976 women, 332 with a history of depression at baseline had an earlier onset of perimenopause during 3 years of follow-up, with perimenopause being defined as changes in menstrual cycle regularity and bleeding patterns. These women also exhibited higher serum follicle stimulating and luteinizing hormone concentrations, and lower estradiol concentrations, than those without depression. The mechanism by which depression might influence these hormones 


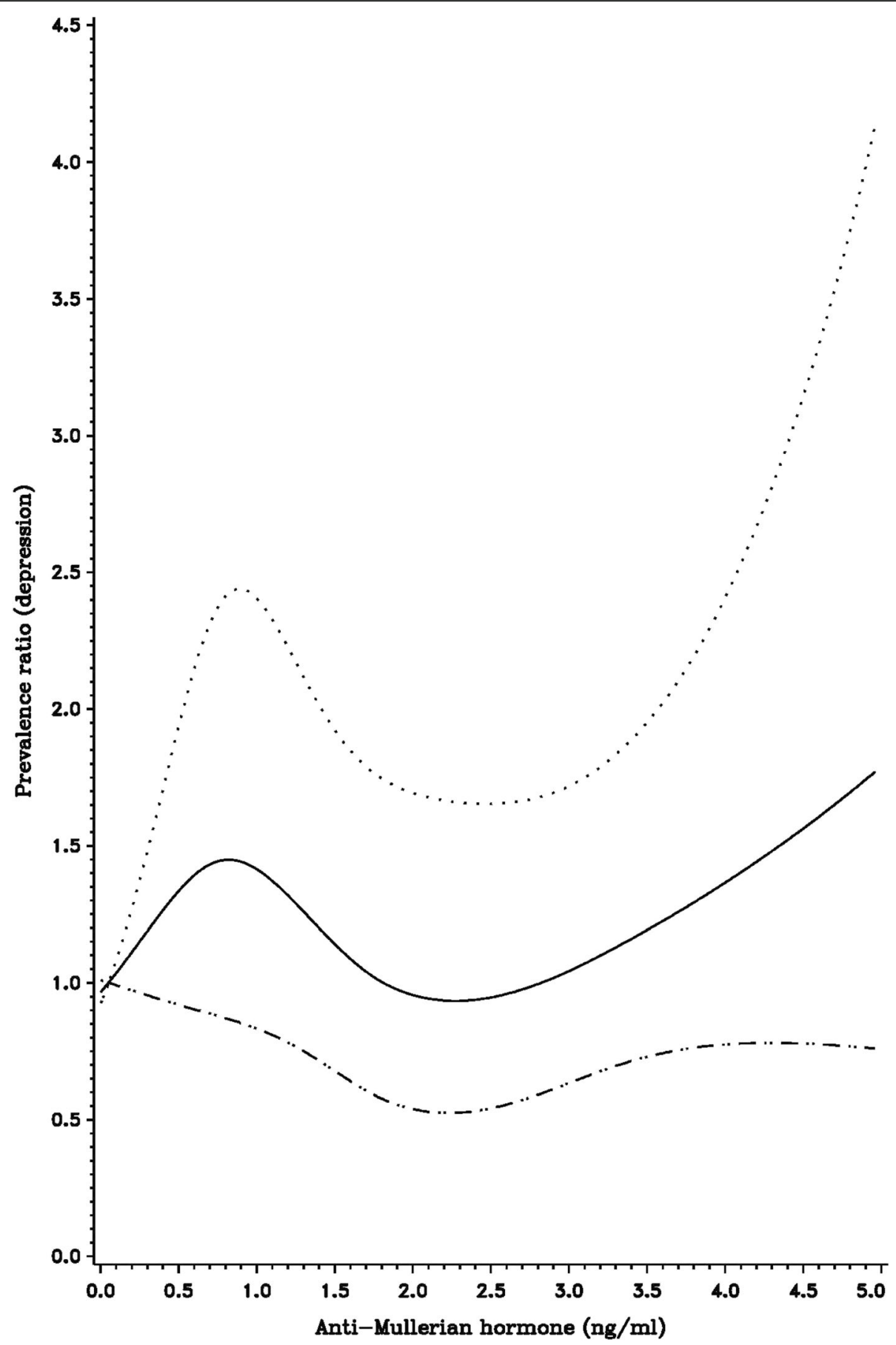

Fig. 3 Restricted cubic spline displaying the association between depression history and AMH levels among women aged 40-44 years at enrollment, with knot points at AMH levels of $0.100,0.750,1.750,3.250$. Adjusted for cycle irregularity, BMl, pack-years of smoking, age at menarche, and history of OC use

is unknown; however, combined with the lack of altered ovarian inhibin B and AMH concentrations, neuroendocrine candidates are likely mediators. The effect of depression on hypothalamic factors that control pituitary gonadotropin secretion, such as $\mathrm{GnRH}$ and kisspeptin, may be worthwhile to investigate.
Our data were limited by the fact that only a subset $(n=369)$ of samples from the larger study group were assayed for $\mathrm{AMH}$, and a greater proportion of depressed women were included in the subcohort relative to the complete HSMC cohort. If selection into the AMH substudy also depended on ovarian reserve (e.g., the 
availability of menstrually-timed blood specimens due to a lower likelihood of amenorrhea/irregular cycling), then the observed positive association between depression and $\mathrm{AMH}$ could be spurious. Likewise, AMH concentrations were assayed in a greater proportion of nulligravid depressed women than nulliparous non-depressed women. If nulligravidity is associated with greater ovarian reserve, this could explain the observed better ovarian reserve among depressed women. This is not likely to be an artifact of age since we did not see any major differences in specimen availability by age.

Laboratory development of AMH immunoassays has changed rapidly in recent years and continues to undergo improvement. The original methods were manual and laborious to perform. Assay protocols were modified as interfering substances were identified. Newer methods now include automation. Nevertheless, we still lack a universal assay calibration which results in different absolute values obtained by each method [27, 28]. Investigators are responsible for knowing which assay is being used and the appropriate reference ranges for that method. Our results were obtained using the most sensitive assay available (Ansh picoAMH), with a lower limit of $6 \mathrm{pg} / \mathrm{mL}$. This is ideal for women of late reproductive age, where AMH levels are expected to be relatively low, and beyond the lower limit of detection $(\sim 100 \mathrm{pg} / \mathrm{mL})$ in other assay methods. The present assay results demonstrate the expected age-related decline in serum AMH levels. In fact, the distribution of AMH concentrations by age (Supplemental Fig. 1) is similar to that observed by Fong et al. who used controls from previous studies with a wide range of timing between assay and data collection, and whose specimens had been thawed and refrozen [48]. In addition, although these specimens had been frozen for several years prior to analysis, any effect of storage would similarly impact samples from depressed and non-depressed women.

A limitation of the current study is the cross-sectional nature of the data. In addition, the HSMC sample overrepresents non-Hispanic white women, which precluded the possibility of examining differences in the associations among women of different racial and ethnic groups.

\section{Conclusions}

In summary, our findings do not support a deleterious effect of depression on ovarian reserve as measured by $\mathrm{AMH}$. These findings are consistent with our earlier assessment of inhibin B and depression.

\section{Supplementary information}

Supplementary information accompanies this paper at https://doi.org/10. 1186/s40695-020-00056-x.

Additional file 1: Figure S1. Restricted cubic spline displaying the association between age and AMH levels, with knot points at AMH levels of $0.100,0.750,1.750,3.250$. Adjusted for BMl and pack-years of smoking Figure S2. Restricted cubic spline displaying the association between pack-years of smoking and $\mathrm{AMH}$ levels, with knot points at AMH levels of $0.100,0.750,1.750,3.250$. Adjusted for age and BMI. Figure S3. Restricted cubic spline displaying the association between BMI and AMH levels, with knot points at AMH levels of $0.100,0.750,1.750,3.250$. Adjusted for age and pack-years of smoking.

\section{Abbreviations}

AMH: Anti-müllerian hormone; BMI: Body mass index; CES-D: Center for Epidemiologic Studies 20-item depression symptoms inventory;

Cl: Confidence interval; DSM-IV: Diagnostic and Statistical Manual of Mental Disorders, fourth edition; HAM-D: Hamilton Rating Scale for Depression; HSMC: Harvard Study of Moods and Cycles; MDD: Major depressive disorder; OC: Oral contraceptives; PCOS: Polycystic ovarian syndrome; PR: Prevalence Ratios; SCID: Structured clinical interviews for depression

\section{Acknowledgments}

We thank Ansh Labs for the generous provision of assay reagents.

\section{Authors' contributions}

SWG analyzed study data and contributed to the writing of the manuscript. LAW and BLH provided epidemiological subject matter expertise, guided the analysis and were major contributors in writing and reviewing the manuscript. GMLM and EEE performed immunoassays, provided subject matter expertise in interpreting results, and contributed to the writing of the paper. All authors read and approved the final manuscript.

\section{Funding}

The Harvard Study of Moods and Cycles was supported by National Institutes of Health (NIH) Grants R01-MH50013 and R01-MH69732.

\section{Availability of data and materials}

The datasets used and/or analyzed during the current study are available from the corresponding author on reasonable request.

\section{Ethics approval and consent to participate}

The HSMC was approved by the Institutional Review Board at Brigham and Women's Hospital and all participants provided written informed consent. All procedures performed in studies involving human participants were in accordance with the ethical standards of the institutional and/or national research committee and with the 1964 Helsinki declaration and its later amendments or comparable ethical standards. Informed consent was obtained from all individual participants included in the study.

Consent for publication

Not applicable.

\section{Competing interests}

Author GMLM has previously received travel support from Ansh labs. The authors declare that they have no other conflict of interest.

\section{Author details}

'Department of Epidemiology, Boston University School of Public Health, 715 Albany St, Boston, MA 02118, USA. ${ }^{2}$ Department of Pathology and Laboratory Medicine, Alpert Medical School at Brown University, 222 Richmond St, Providence, RI 02903, USA. ${ }^{3}$ Women and Infants Hospital, 101 Dudley Street, Providence, RI 02905, USA.

Received: 5 November 2019 Accepted: 20 July 2020

Published online: 01 September 2020

\section{References}

1. Sowers MR, Crawford S, Sternfeld B, Morganstein D, Gold E, Greendale G, et al. SWAN: a multi-center, multi-ethnic, community-based cohort study of women and the menopausal transition. In: Kelsey J, Marcus R, editors. Lobo R. Menopause: Biology and Pathobiology; 2000. p. 175-88.

2. Allshouse A, Pavlovic J, Santoro N. Menstrual cycle hormone changes associated with reproductive aging and how they may relate to symptoms. Obstet Gynecol Clin N Am. 2018 Dec;45(4):613-28. 
3. Soares CN. Mood disorders in midlife women: understanding the critical window and its clinical implications. Menopause. 2014 Feb;21(2):198-206.

4. Freeman EW, Sammel MD, Lin H, Nelson DB. Associations of hormones and menopausal status with depressed mood in women with no history of depression. Arch Gen Psychiatry. 2006 Apr;63(4):375-82.

5. Schmidt PJ, Rubinow DR. Sex hormones and mood in the perimenopause. Ann N Y Acad Sci. 2009 Oct;1179:70-85.

6. Dolleman M, Faddy MJ, van Disseldorp J, van der Schouw YT, Messow CM, Leader B, et al. The relationship between anti-Mullerian hormone in women receiving fertility assessments and age at menopause in subfertile women: evidence from large population studies. J Clin Endocrinol Metab. 2013 May; 98(5):1946-53.

7. Baird DD, Steiner AZ. Anti-Mullerian hormone: a potential new tool in epidemiologic studies of female fecundability. Am J Epidemiol. 2012 Feb; 175(4):245-9.

8. Finkelstein JS, Lee H, Karlamangla A, Neer RM, Sluss PM, Burnett-Bowie S$\mathrm{AM}$, et al. Antimullerian hormone and impending menopause in late reproductive age: the study of Women's health across the nation. J Clin Endocrinol Metab. 2020 Apr;105(4):e1862-71.

9. Depmann M, Eijkemans MJ, Broer SL, Scheffer GJ, van Rooij I, Laven JS, et al. Does anti-Mullerian hormone predict menopause in the general population? Results of a prospective ongoing cohort study. Hum Reprod. 2016;31(7):1579-87.

10. Bertone-Johnson ER, Manson JE, Purdue-Smithe AC, Steiner AZ, Eliassen AH, Hankinson SE, et al. Anti-Müllerian hormone levels and incidence of early natural menopause in a prospective study. Hum Reprod. 2018 Jun;33(6): $1175-82$.

11. Ramezani Tehrani F, Dolleman M, van Disseldorp J, Broer SL, Azizi F, Solaymani-Dodaran M, et al. Predicting menopausal age with anti-Mullerian hormone: a cross-validation study of two existing models. Climacteric. 2014 Oct;17(5):583-90

12. Iwase A, Nakamura T, Osuka S, Takikawa S, Goto M, Kikkawa F. Anti-Müllerian hormone as a marker of ovarian reserve: what have we learned, and what should we know?. Reprod Med Biol [Internet] 2016;15(3):127-136. Available from: https://onlinelibrary.wiley.com/doi/abs/10.1007/s12522-015-0227-3.

13. Lambert-Messerlian G, Plante B, Eklund E, Raker C, Moore R. Levels of antimüllerian hormone in serum during the normal menstrual cycle. Fertil Steril. 2016;105(1):213.e1.

14. Broer SL, Broekmans FJ, Laven JS, Fauser BC. Anti-Mullerian hormone: ovarian reserve testing and its potential clinical implications. Hum Reprod Update. 2014;20(5):688-701.

15. Gold EB, Bromberger J, Crawford S, Samuels S, Greendale GA, Harlow SD, et al. Factors associated with age at natural menopause in a multiethnic sample of midlife women. Am J Epidemiol. 2001 May;153(9):865-74.

16. Oh SR, Choe SY, Cho YJ. Clinical application of serum anti-Müllerian hormone in women. Clin Exp Reprod Med. 2019 Jun;46(2):50-9.

17. Bleil ME, Gregorich SE, Adler NE, Sternfeld B, Rosen MP, Cedars MI. Race/ ethnic disparities in reproductive age: an examination of ovarian reserve estimates across four race/ethnic groups of healthy, regularly cycling women. Fertil Steril. 2014 Jan;101(1):199-207.

18. Gold EB, Crawford SL, Avis NE, Crandall CJ, Matthews KA, Waetjen LE, et al. Factors related to age at natural menopause: Iongitudinal analyses from SWAN. Am J Epidemiol. 2013 Jul;178(1):70-83.

19. Harlow BL, Cramer DW, Annis KM. Association of medically treated depression and age at natural menopause. Am J Epidemiol. 1995 Jun; 141(12):1170-6.

20. Harlow BL, Wise LA, Otto MW, Soares CN, Cohen LS. Depression and its influence on reproductive endocrine and menstrual cycle markers associated with perimenopause: the Harvard study of moods and cycles. Arch Gen Psychiatry. 2003 Jan;60(1):29-36.

21. Lewinsohn PM, Seeley JR, Roberts RE, Allen NB. Center for Epidemiologic Studies Depression Scale (CES-D) as a screening instrument for depression among community-residing older adults. Psychol Aging. 1997 Jun;12(2):277-87.

22. Spitzer R, Williams J, Gibbon M. Structured clinical interview for DSM-IV, outpatient version (SCID-OP). New York: Biometrics Research Department, New York State Psychiatric Institute; 1996.

23. Hamilton M. A rating scale for depression. J Neurol Neurosurg Psychiatry. 1960 Feb;23:56-62.

24. Harlow BL, Cohen LS, Otto MW, Liberman RF, Spiegelman D, Cramer DW. Demographic, family, and occupational characteristics associated with major depression: the Harvard study of moods and cycles. Acta Psychiatr Scand
[Internet]. 2002;105(3):209-17 Available from: http://www.ingentaconnect. com/content/mksg/acp/2002/00000105/00000003/art00008.

25. Harlow BL, Cohen LS, Otto MW, Spiegelman D, Cramer DW. Prevalence and predictors of depressive symptoms in older premenopausal women: the Harvard study of moods and cycles. Arch Gen Psychiatry. 1999;56(5):418-24.

26. Lambert-Messerlian GM, Harlow BL. The influence of depression, body mass index, and smoking on Serum Inhibin B levels in late reproductive-aged women. J Clin Endocrinol Metab [Internet] 2006;91(4):1496-1500. Available from: http://dx.doi.org/10.1210/jc.2005-2515.

27. Nelson SM, Pastuszek E, Kloss G, Malinowska I, Liss J, Lukaszuk A, et al. Two new automated, compared with two enzyme-linked immunosorbent, antimullerian hormone assays. Fertil Steril. 2015 Oct;104(4):1016-1021.e6.

28. Su HI, Sammel MD, Homer M V, Bui K, Haunschild C, Stanczyk FZ. Comparability of antimullerian hormone levels among commercially available immunoassays. Fertil Steril. 2014 Jun;101(6):1766-72.e1.

29. La Marca A, Ferraretti AP, Palermo R, Ubaldi FM. The use of ovarian reserve markers in IVF clinical practice: a national consensus. Gynecol Endocrinol Off J Int Soc Gynecol Endocrinol. 2016;32(1):1-5.

30. Dewailly D, Gronier H, Poncelet E, Robin G, Leroy M, Pigny P, et al. Diagnosis of polycystic ovary syndrome (PCOS): revisiting the threshold values of follicle count on ultrasound and of the serum AMH level for the definition of polycystic ovaries. Hum Reprod. 2011 Nov;26(11):3123-9.

31. Ficicioglu C, Kutlu T, Baglam E, Bakacak Z. Early follicular antimullerian hormone as an indicator of ovarian reserve. Fertil Steril. 2006 Mar;85(3):592-6.

32. Zou G. A Modified Poisson Regression Approach to Prospective Studies with Binary Data. Am J Epidemiol [Internet]. 2004 Apr;159(7):702-6. Available from: http://www.ncbi.nlm.nih.gov/pubmed/15033648.

33. Durrleman S, Simon R. Flexible regression models with cubic splines. Stat Med. 1989 May;8(5):551-61

34. de Vet A, Laven JSE, de Jong FH, Themmen APN, Fauser BCJM. Antimüllerian hormone serum levels: a putative marker for ovarian aging. Vol. 77.

35. Anderson RA, Nelson SM, Wallace WH. Measuring anti-Mullerian hormone for the assessment of ovarian reserve: when and for whom is it indicated? Maturitas. 2012 Jan;71(1):28-33.

36. Jung S, Allen N, Arslan AA, Baglietto L, Brinton LA, Egleston BL, et al. Demographic, lifestyle, and other factors in relation to anti-Müllerian hormone levels in mostly late premenopausal women. Fertil Steril. 2017; 107(4):1022.e2.

37. Shaw CM, Stanczyk FZ, Egleston BL, Kahle LL, Spittle CS, Godwin AK, et al. Serum antimüllerian hormone in healthy premenopausal women. Fertil Steril [Internet]. 2011 30;95(8):2718-21. Available from: https://www.ncbi.nlm. nih.gov/pubmed/21704216.

38. Plante BJ, Cooper GS, Baird DD, Steiner AZ. The impact of smoking on antimullerian hormone levels in women aged 38 to 50 years. Menopause. 2010;17(3):571-6.

39. La Marca A, Sighinolfi G, Giulini S, Traglia M, Argento C, Sala C, et al. Normal serum concentrations of anti-Müllerian hormone in women with regular menstrual cycles. Reprod BioMed Online. 2010 Oct;21(4):463-9.

40. Moslehi N, Shab-Bidar S, Ramezani Tehrani F, Mirmiran P, Azizi F. Is ovarian reserve associated with body mass index and obesity in reproductive aged women? A meta-analysis Menopause. 2018 Sep;25(9):1046-55.

41. Piouka A, Farmakiotis D, Katsikis I, Macut D, Gerou S, Panidis D. AntiMullerian hormone levels reflect severity of PCOS but are negatively influenced by obesity: relationship with increased luteinizing hormone levels. Am J Physiol Endocrinol Metab. 2009 Feb;296(2):E238-43.

42. Steiner AZ, Stanczyk FZ, Patel S, Edelman A. Antimullerian hormone and obesity: insights in oral contraceptive users. Contraception. 2010 Mar;81(3):245-8.

43. Halawaty S, ElKattan E, Azab H, ElGhamry N, Al-Inany H. Effect of obesity on parameters of ovarian reserve in premenopausal women. J Obstet Gynaecol Canada JOGC = J d'obstetrique Gynecol du Canada JOGC. 2010 Jul;32(7): 687-90.

44. Skałba P, Cygal A, Madej P, Dąbkowska-Huć A, Sikora J, Martirosian G, et al. Is the plasma anti-Müllerian hormone $(\mathrm{AMH})$ level associated with body weight and metabolic, and hormonal disturbances in women with and without polycystic ovary syndrome? Eur J Obstet Gynecol Reprod Biol. 2011 Oct; 158(2):254-9.

45. Jurczak A, Szkup M, Samochowiec A, Grzywacz A, Samochowiec J, Karakiewicz B, et al. An analysis of the influence of selected genetic and hormonal factors on the occurrence of depressive symptoms in latereproductive-age women. Int J Environ Res Public Health [Internet]. 2015 
Apr;12(4):3547-63. Available from: http://www.ncbi.nlm.nih.gov/pubmed/25 826396.

46. Dong YZ, Zhou FJ, Sun YP. Psychological stress is related to a decrease of serum anti-mullerian hormone level in infertile women. Reprod Biol Endocrinol. 2017 Jul;15(1):4.

47. Sowers MR, Eyvazzadeh AD, McConnell D, Yosef M, Jannausch ML, Zhang D, et al. Anti-mullerian hormone and inhibin B in the definition of ovarian aging and the menopause transition. J Clin Endocrinol Metab. 2008 Sep; 93(9):3478-83.

48. Lie Fong S, Visser JA, Welt CK, de Rijke YB, Eijkemans MJC, Broekmans FJ, et al. Serum anti-mullerian hormone levels in healthy females: a nomogram ranging from infancy to adulthood. J Clin Endocrinol Metab. 2012 Dec; 97(12):4650-5.

\section{Publisher's Note}

Springer Nature remains neutral with regard to jurisdictional claims in published maps and institutional affiliations.

Ready to submit your research? Choose BMC and benefit from:

- fast, convenient online submission

- thorough peer review by experienced researchers in your field

- rapid publication on acceptance

- support for research data, including large and complex data types

- gold Open Access which fosters wider collaboration and increased citations

- maximum visibility for your research: over $100 \mathrm{M}$ website views per year

At BMC, research is always in progress.

Learn more biomedcentral.com/submissions 